\title{
La novela El Crrioso impertinente en la poética de la ficción del Quijote
}

\author{
Jorge Valenzuetua Garcés \\ Universidad Nacional Mayor de San Marcos \\ $\&$
}

Restmen

Concebida como una novela dentro de la gran novela Don Quijote de la Mancha, la de El Arriaso impertinente puede considerarse camo uno de los mejores ejemplos de la maestría de Cervantes en el empleo de ciertos rearsos técnicos y de la asimilación de la tradición narrativa de su época. La novela, un romance italiano, reconstnuye una historia de supuestas traiciones, celos y deslealtades entre dos amigos y la mujer de uno de ellos. Nuestro dbjetivo es, a partir de la poética de la ficción del arijote, explicar las razones que llevaron al autor a incluir esta pequeña novela dentro de su gran dora y a analizar las consecuencias de esta inserción.

Palabras claves: El arioso impert inente, Don Quijote de la Mancha, Miguel de Cervantes, novela modema.

\section{Abstract}

A novel whitin a novel, El arioso impertinente reveals Cervantes as a master of thecnicalities in the making of a novel. The author of this article, taking into account cervante's poetics of fiction, ponders about the reasons Cervantes might have had to include this novel into his greater masterwork. Analyzes, also, the consequences of this insertion.

Key words: El arrioso impertinente, Don Quijote de la Mancha, Miguel de Cervantes, modem novel.

\section{Introducción}

T a novela Don Quijote de la Mancha es, ante todo, muchas novelas, Lun laboratorio en el que es posible, como lectores, acceder a una número infinito de lecturas y vivir diversas experiencias a partir de la multiplicidad de historias contenidas y articuladas a la gran epopeya personal de don Quijote. 
En su estudio sobre Cervantes (1989) , Stephen Gilman renuncia a seguir preguntandose sobre los temas tratados en el Quijote, la época en la que fue escrita, los tipos humanos representados o los ideales a partir de los que fue concebida. Su curiosidad se orienta por otros caminos, aquellos en los que cuenta la recepción del texto, la forma en que el lector -incluso el intratextual-actualiza ciertos procedimientos de lectura. Así, para Gilman resulta importante preguntarse lo siguiente: ¿qué les hacen las novelas a sus lectores? y en el caso de Cervantes: ¿qué efectos produce en el lector la lectura del Quijote? (15) .

Para Gilman, Cervantes aprendió en el Quijote «cómo explotar (dar origen, inventar, descubrir) al máximo las milagrosas posibilidades propias de la ficción: es decir cómo hacer posible que aumentemos nuestra identidad y refresquemos nuestro rancio depósito de experiencias en el acto de entregarnos a las vidas de ficción de una manera mucho más intensa y significativamente más viva de lo que en realidad somos». (1989: 21)

En esta dirección, Mario Vargas Llosa ha sostenido, por su parte, que en el quijote la ficción « está por todas partes, en las peripecias, en las bocas, y hasta en el aire que respiran los personajes» (2004:XVIII) Sirvan, pues, estas dos apreciaciones para situar muestra hipótesis de trabajo sobre la novela El arrioso impertinente.

Desde nuestro punto de vista, esta breve novela puede ser considerada como uno de los modelos textuales que sirven para confirmar la poética de la ficción cervantina. En efecto, su presencia y pertinencia en el despliegue estratégico que presenta el plan general del Quijote y el efecto que produce en el lector, además del juicio que sobre ella se emite por los propios personajes que la escuchan, son instrumentos que nos pueden ayudar a definir el tipo de novela y lector que imaginaba Cervantes.

\section{La poética de la fícción del quijote}

\subsection{Io ficticio novelado}

En el Quijote se puede comprobar, con facilidad, el siguiente hecho: a lo largo de toda la novela se hace referencia a otros libros (a su poder de persuasión, a su calidad y a su verdad o su mentira). En efecto, la 
presencia de ese otro mundo constituido por las historias de los libros que se leen o sobre los que se abre un breve debate, es importante y forma parte de la estructura de la novela. Este es un mecanismo-quizá el principal- a través del aal se infiltra la ficción en la «realidad» que impone la novela. El otro es el de la imaginación desatada de los personajes, la desbordada forma en que, mentalmente, transforman la realidad. En ambos casos, la novela nos permite acceder, a través de comentarios, a una teoría de la ficción, a lo que en la novela se tiene como un conjunto de principios que discriminan entre lo que es real y verdadero y lo que es falso o engañoso.

Sin embargo, como sostiene José María Pozuelo, «lo verdaderamente importante no es la poética (teoría de la ficción) presente en el Quijote sino la poética de la ficción del Quijote....». (1993:26) , es decir, el papel que cumplen todas esas textualidades vinculadas entre sí en la novela y la forma en que hacen ficción y la constnuyen. Cuestión, sin duda, de ínoble estructural y que rebasa largamente el componente temático.

A eso se refiere sin duda Pozuelo, cuando sostiene que «la frontera ficción/ realidad en el Quijote no puede situarse en el mi.smo rango, ni en el mismo nivel analítico que muchos otros temas sobre los que en el Quijote se diserta, como el de los moriscos, la mujer, la libertad o el amor. La frontera ficción/ realidad, continúa Pozuelo, compromete la unidad y la totalidad del diseño artístico de toda la novela, afecta a lo que Bajtin llamaría su forma arquitectónica y no es por consiguiente un asunto o ingrediente con valor referencial, sino con valor sígnico, formal y definidoramente artístico. (...) Es un vector que cruza desde la constitución misma de la personalidad enferma de su héroe, hasta la imaginación de una Dulcinea o las promesas que mueven a Sancho, las múltiples parodias sobre la literatura anterior incluidas a lo largo de la dora, etc. (...) límite que, insisto, no es un tema sino el dispositivo estructurador o dominante de su diseño artístico» . (1993:27)

\subsection{Las historias relatadas en el Quijote}

Si partimos del hecho de que en el Quijote la cuestión de la realidad y la ficción no es un tema sino el eje que estructura el relato, bien vale la pena interrogarse sobre la forma en que una novela menor como la de El arrioso impertinente es inscrita en el plan general de la dora y la forma en que contribuye a esa tensión entre realidad y ficción. 
Ia crítica (Castro, 1972: 126) se ha ocupado in extenso de la inserción de las diversas novelas que se intenpolan a la historia central del Quijote. Por ejemplo, se ha dicho que «la presencia de una novela busca acentuar la variedad de los «cuentos y episodios» que se alternan con los lances del protagonista». (Cervantes, 2004: 326 nota 31). Según Francisco Rico, en la época de la escritura del Quijote, un principio en las artes recomendaba que se escribiera, teniendo como patrón, la variedad de la naturaleza. De hecho en el mismo Quijote (Capítulo XXVIII) se hace referencia a este principio: «gozamos ahora en nuestra edad, necesitada de alegres entretenimientos, no sólo de la dulzura de su verdadera historia (la del Quijote) , si no de los cuentos y episoolios de ella, que en parte no son menos agradables y artificiosos y verdaderos que la mi.sma historia...». (2004: 274) .

Es cierto, como dice Rico, que este procedimiento busca «la altermancia de temas y modalidades literarias (pastoril, sentimental, de aventuras, etc.) del mismo modo que se procura la variedad en los lances de don Quijote y Sancho» (Cervantes, 2004: 274 nota 1) . Pero no lo es menos que esta sea, después de todo, una forma de componer atendiendo a un cuestión central : el reconocimiento de un segundo nivel de realidad y la importancia de ese segundo nivel para entender el primer nivel en el que la ficción ha devastado la imaginación de sus personajes o se ha convertido en un mecanismo a través del cual se puede acceder a alguna clase de bien o a la felicidad.

En el quijote se abren debates sobre los libros que, por alguna razón, caen en las manos de los personajes. Esos debates, que se producen después de la lectura y la atenta escucha de los involucrados en el acto, suponen, normalmente, una valoración, son metadiscursos críticas que reflexionan sobre la novela y sobre la ficción.

\section{La novela 터 curioso impertinente en el sistema general del Quijote}

\subsection{Las novelas de caballería en el Quijote y la novela de EI arrioso impertinente}

Luego que don Quijote y Sancho han llegado nuevamente a la venta y el primero se ha quedado dormido (capítulo XXXII de la primera 
parte) se inicia una conversación entre el ventero, la ventera, su hija y Maritomes a propósito de las palabras del cura quien viene de decir que los libros de caballería le habían hecho perder el juicio al hidalgo caballero. Allí se da pie a una discusión sobre los libros de caballería. El ventero es quien sostiene que le parece imposible que estos libros pudiesen haber contribuido a que don Quijote perdiese la razón y argumenta, más bien, que ese tipo de novelas le «han dado la vida, no solo a mi, sino a muchos otros». (Cervantes, 2004:321) y que escuchar las historias de caballerías «nos quita mil canas» (2004:321) . Agrega, además, que «de mi sé decir que cuando oyo decir aquellos furibundos y terribles golpes que los caballeros pegan, que me toma gana de hacer otro tanto, y que querría estar oyéndolos noches y días». (2004:321) La ventera, por su parte, opina favorablemente sobre estas novelas y dice que cuando su marido las está escuchando no riñe con ella. A su vez Maritomes pondera las novelas y sostiene que «gusto mucho de oír aquellas cosas, que son muy lindas, y más cuando cuentan que se está la otra señora debajo de unos naranjos abrazada con su caballero. (...) Digo que todb esto es casa de mieles». (321)

De las opiniones vertidas por los personajes se puede deducir que todos se encuentran agradecidos por el placer que les brinda la ficción por diversas razones. Es decir, las novelas de caballerías son importantes en sus vidas porque las afectan positivamente y las transforman momentáneamente. Y bien, ¿qué quiere decir que la ficción sea importante en la vida de los personajes?

Si nos atenemos a sus declaraciones, escuchar novelas de caballería da vida, es decir, permiten vivir, hacer más intensa la vida, permiten olvidar los pesares, las incomodidades, las desgracias. Para el ventero escuchar las novelas es tan real que siente el deseo de golpear como los caballeros, de ser como ellos. Para la ventera, que su esposo escuche las novelas le permite disfnutar en paz su matrimonio y evitar las riñas. Para Neritomes, escucharlas le permite imaginarse como una mujer amada.

Placer, utilidad, compensación, liberación, ejercicio de la imaginación son las consecuencias de haber escuchado una ficción, así, pues, las novelas de caballería se convierten en un espacio en el que es posible ser otro, es decir, aquel que se desea y, sobre todo, el espacio en el que se puede ser feliz. 
Escuchar novelas en el Quijote es parte de la vida; diríamos, incluso, es una costumbre que se practica siempre que se puede y cuando se está en disposición de hacerlo. Es, claro está, una necesidad en el mundo que construye la novela, una necesidad a veces impostergable.

Ahora bien, ¿qué es lo que explica que Cervantes haya convertido a la ficción en una necesidad para los personajes y sobre todo para su protagonista?

Las primeras explicaciones tienen que ver con el código estético dentro del que se inscribe el arijote; es decir, el Barroco. Caracterizado por ser esencialmente expresión de una crisis espiritual y moral, el Barroco da cuenta de la crisis de valores que habían consolidado la ideología del Renacimiento, valores asociados a la armonía y perfección del hombre situado en el centro de la naturaleza. Ahora, lejos de la seguridad que le habían dado las creencias generadas a partir de la razón, la necesidad de expresar la avalancha de contradicciones de la época, planteaba nuevas vías de representación acordes con la crisis.

Temas como la inestabilidad y desintegración de la realidad, central en el Quijote, la lucha entre lo profano y lo sagrado u oposiciones radicales e irreductibles que reflejaban esa pugna que tenía lugar en la conciencia de esos hombres desgarrados, se convierten en el centro del interés de los escritores de Siglo de Oro. Como correlato de estos temas, la aparición de lo excesivo o exagerado o grotesco, deformado por estrategias como la ironía y el sarcasmo, se constituyen en las vías de representación de un mundo casi inaprensible.

Así, una narrativa de los límites y de las abismales oposiciones podría ser la del Barroco, una narrativa de la gravedad y de la importancia de cuestiones como las del espíritu y la materia que, finalmente, encarma en el Quijote a través de ese magnífico recurso que es la ficción.

Ahora bien, ¿por qué en el centro de esa narrativa en la que también se recuperan por necesidad y por placer los valores de las novelas de caballería, el autor implícito del Quijote decide incluir una novela italiana camo la de El curioso impertinente?

En el capítulo XXXII de la primera parte, luego de que toda la cuadrill la de don Quijote ha llegado a la venta, el cura tiene un diálogo con Cardenio sobre las novelas de caballería, a propósito de algunas 
de ellas dejadas en una maleta, por un huésped. El cura aprovecha el desarreglo mental de don Quijote para decir que en esas novelas ni los hechos narrados ni los personajes que los llevan a cabo han existido «porque todo es compostura y ficción de ingeniosos ociosos, que los compusieron para el efecto que vos decís de entretener el tiempo (... ) Porque os juro que nunca tales caballeros fueron en el mundo, ni tales hazañas ni disparates acontecieron en él.» (Cervantes, 2004: 324). Ante esta respuesta, el ventero duda de la veracidad de las palabras del cura argumentando que las autoridades no podrían permitir la publicación de mentiras. El cura insiste en que los libros de caballería son pura invención. Finalmente le advierte que si no toma por mentiras e invenciones lo que cuentan esos libros puede correr el riesgo de cojear «del mi.smo pie que cojea vuestro huésped don Quijote.» (Cervantes, 2004:324).

Este es el momento en que el ventero decide llevarse la maleta que contiene entre otros papeles la novela de El curioso impertinente. El cura lo detiene y decide leerla, asegurando que «si la novela me contenta, me la habéis de dejar trasladar (copiar) ». Se cierra el capítulo con una acotación del cura que dice «quiero leerla por curiosidad siquiera: quizá tenorá alguna (ariosidad o cosa interesante) de gusto.» (2004: 327)

Hemos reconstruido la aparición de la novela de El curioso impert inente porque consideramos que la forma en que lo hace no es gratuita. Aparece, como se ve, vinculada casualmente con las novelas de caballerías, pero también aparece como una novela que se va a leer para «entretener el tiempo».

La novela es «leída» no solo por el cura, quien es el encargado de hacerlo intratextualmente, sino por todos nosotros, que actualizamos en la lectura los deseos e indicaciones del arra. Así, el texto es inscrito en el sistema general del Quijote, como una novela que será leída de forma condicionada y, ciertamente, de cara al paradigma de las novelas de caballerías que ya ha sido valorado positivamente por los propios personajes en una discusión que se da en el primer nivel de realidad que construye la novela, pero también criticada por el cura.

Enmarcada dentro de Don Quijote de la Mancha, la novela El curioso impert inente que ocupa los capítulos XXXII, XXXIII, XXXIV Y XXXV, tiene 
el semblante de las novelas ejemplares publicadas por Cervantes en 1613. Escritas, sin embargo, antes del Quijote, suponen un aprendizaje del paradigma de la novela italiana creado por Bocaccio y los cuentistas italianos.

La historia transcurre en Florencia y vincula a dos amigos, Lotario y Anselmo y a la esposa de este, en una serie de acciones propias de los romances italianos. El propósito que mueve la acción tiene que ver con el deseo de Anselmo de comprobar, a través de su amigo, si su esposa es tan fiel y virtuosa como aparenta ser. La novela crece en complicaciones, avances y retrocesos, y su dinámica apunta a configurar un tipo humano: el esposo desconfiado y curioso. Ciertamente Anselmo parte de un prejuicio: la mujer es un animal imperfecto cuya vida debe apuntar, sorteando inconvenientes, a la virtud.

El capítulo XXXV del Quijote, tituladb Donde se da fin a la novela de El arioso impertinente, se inicia con una nptura de la lectura de la novela que la cuadrilla está escuchando de boca del cura. Don Quijote ha despertado de su letargo e, imaginando enfrentar a una enemigo de la Princesa Micomicona, está acuchillando a los cueros de vino de la venta. Controlado ese violento avance, el cura continua leyendo la novela hasta que la termina. En ese momento emite el siguiente juicio:

\footnotetext{
«Bien-dijo el cura-me parece esta novela, pero no me puedo persuadir que esto sea verdad; y si es fingido, fingió mal el autor, porque no se puede imaginar que haya marido tan necio, que se quiera hacer tan costosa experiencia como Anselmo. Si este caso se pusiera entre un galán y una dama, pudiérase llevar, pero entre marido y mujer, algo tiene del imposible; y en lo que toca al modo de contarle, no me descontenta.» (Cervantes, 2004; 374)
}

Llama la atención la forma en que el cura pondera sobre una novela realista idealista como la de El arrioso impertinente. En principio destaca que la novela no lo ha persuadido de su verdad, así como las novelas de caballería, de las que también desconfía. Es decir, el cura parte del hecho de que todas las novelas son verdaderas o falsas y que pueden crear la ilusión de la verdad, si el autor sabe fingir bien. Rues bien, ¿de qué se trata todo esto? 


\section{La poética de la ficción cervantina y la novela Ell Curioso impertinente}

Una de las constataciones més productivas y sugerentes a partir de la lectura del Quijote, tiene que ver con el hedho de que, entre otras virtudes, es un compendio de las formas discursivas previas a su aparición. Como sostiene Pozuelos Yvancós (1993:30), el gran afán de Cervantes es convertir a su novela en un espacio en el que estas disarsividades lleguen a naturalizarse (ser vida yno literatura). Es visible que esta naturalización se pretende llevar a cabo a través de la acción de la novela; eso, por ejemplo, sucede con las novelas de caballerías que se hacen vida misma a través de la acción de los personajes.

Aunque hay un consenso sobre el efecto positivo de estas novelas en las vidas de ciertos personajes, sin embargo el cura por ejemplo es un crítico de ellas. Para él debe quedar bien claro que narran acontecimientos que nunca ocurrieron.

Pozuelos Yvancós dice que lo fundamental de todo este proceso de naturalización es que se lleva a cabo «poéticamente a los ojos del lector, no es un «contenido» casi nunca, sino una historia con igual rango y al mismo nivel de representación de la propia de don Quijote y Sancho (que especularmente remite también a esa literatura previa) .» (1993: 30-31) Pozuelos sostiene, también, que el discurso novelístico del Quijote es «un discurso nacido por los libros, que constituye un debate sobre los libros, sin dejar de ser nunca, él mismo, un libro donde el límite de lo ficcional-verdadero termina por ser genialmente especular, borrado y reiniciado a cada momento». (1993:28)

Así, pues, puede entenderse al Quijote como la ficción por antonomasia, el libro madre cuya estrategia central, es decir la naturalización de todas las historias contenidas en el libro, constnuye y destruye permanentemente los límites entre la ficción y la realidad.

Ahora bien, ¿qué papel juega la lectura intra y extratextual de la novela o romanzo de El curioso impertinente en el sistema general del Quijote desde esta perspectiva de análisis?

En principio debemos situar a esta novela dentro de la gran discusión que se produjo a propósito del Orlando furioso de Ludovico Ariosto. Recordemos que en esa discusión se opusieron, de un lado, 
los que defendían el romance de Ariosto y las virtualidades de la invención puestas en práctica en su novela y, por otro, los que seguían a pie juntillas el precepto de la imitatio naturae. En ese contexto el romance de Ariosto llevaba a su máximo esplendor la idea de que lo más increíble puede resultar verdadero y lo falso puede resultar creíble. Es decir, con su Orlando furioso, Ariosto prueba que el éxito del texto radica en la composición del mismo, en el efecto de verosimilitud que llega a conseguir el autor. No en la verdad contenida en él. Su argumento era fuerte: las cosas no son verdaderas o dejan de serlo en sí mi.smas, se hacen verdaderas al lector mediante la composición artística.

Ahora bien, no es difícil constatar cómo Cervantes absorbe y revoluciona este precepto de la literatura renacentista para utilizarla en su magnífica novela. Ya sabemos por las reflexiones y opiniones vertidas a lo largo del Quijote, que lo que més disgusta al narrador, de las novelas de caballerías, no es que traten de cosas falsas, sino que no sean verosímiles, lo que, desde su punto de vista, es determinante en que no sean buenas.

Ahora bien, si uno doserva con atención, el cura hace la valoración de la novela de Ell curioso impertinente desde la perspectiva valorativa de aquellos que defendían los presupuestos del romance italiano, pero la está leyendo como si fuera una novela de caballería. La novela, dice el cura, no es verosímil, «no me puedo persuadir de que lo que cuenta sea verdad. Además si es fingido, fingió mal el autor. En lo que toca al modo de contarle, no me descontenta.» Es decir, la presencia de la novela de El curioso impertinente cumple varias funciones, y no por la voz del cura que la critica, sino por el narrador implícito: atiende al valor de las novelas de caballería persuadidas de un notable valor compositivo aunque no verdadero, cuestiona el hecho de que las novelas deban de ser verdaderas para ser buenas novelas y, sobre todo, fomenta el proceso desficcionalizador de las vidas de Don Quijote, Sancho y de todos los personajes que los rodean al enmarcarse dentro de la gran historia de aventuras que finalmente es el Quijote.

Uno de los más grandes méritos del Quijote es que problematiza y enriquece los límites de la representación heredada de los romances (novela italiana) de la tradición medieval (Pozuelos, 2004:46). La mejor 
forma es incluyendo a la novela del El arrioso impertinente en el espacio creado por ella.

A partir de lo dicho, puede deducirse que Cervantes buscaba naturalizar los modelos de la tradición previa para llevar a la práctica su ideal de novela madre, una novela capaz de trabajar cualquier tema. por ello la génesis del Quijote es casi una emanación natural de las circunstancias literarias de su tiempo y, su poética de la ficción, la matriz desde la cual lo real asume, en su tiempo, un rostro nuevo. (Pozuelos, 1993:51)

\section{Referencias bibliográficas}

CASTRO, Américo (1972) : El pensamiento de Cervantes. Editorial Noguer S.A., Madrid.

CERVANIES, Miguel de (2004) [1605-1615] : Don Quijote de la Mancha. Real Academia Española, Asociación de Academias de la Lengua Española, San Pablo.

GIIMAN, Stephen (1989) : La novela según Cervantes. Fondo de Cultura Económica, México.

POZUEL Y YVANCOS, José María (1993) : Poética de la ficción. Editorial Sintesis, Madrid.

VARGAS LIOSA, Mario (2004) : «Una novela para el siglo XXI». En: Don Quijote de la Mancha. Real Academia Española, Asociación de Academias de la Lengua Española, San Pablo; pp. XIII-XXVIII. 